\title{
Interactive comment on "Practitioners' viewpoints on citizen science in water management: a case study in Dutch regional water resource management" by Ellen Minkman et al.
}

\section{S. Abu Shoaib (Referee)}

shoaibmila@yahoo.com

Received and published: 19 October 2016

s.abushoaib@unsw.edu.au

The authors have submitted a thought-provoking paper on "Practitioners' viewpoints on citizen science in water management. Use of Q-methodological approach made the paper more interesting. I enjoyed reading the manuscript; it is very well written and easy to follow. The subject is timely and fits the journal scope well. However I believe it can be improved significantly and the message can be better presented. I recommend minor revision. Below are my comments that may be useful to the authors in updating the manuscript.

Printer-friendly version

Discussion paper 
1. The paper discusses a very interesting aspect of citizen science in water resource management which is usually ignored. One of the most important parts of citizen science could be use of modelling simulation and prediction. In page 2, paragraph 3, line 21 of the manuscript, mentioned the process of decision making of water management. But the manuscript did not address the process development of water management that is vital for decision making. I would suggest, incorporate a complete section or a paragraph focusing recent development of modelling and prediction tools of water management. A unified approach for process-based hydrologic modeling [Clark et al., 2015] and a metric for attributing variability in modelled streamflows [Shoaib et al., 2016] could be useful reference to add in this context.

2. Applied $Q$ methodology is subjective in nature, and findings contain possible bias. $A$ framework to reduce bias from this approach can be outlined to strengthen the content of the paper.

3. I couldn't evaluate the result section because the figures and tables are not presented properly. Captions fail to explain the figures and tables properly. I would suggest to present the figure and tables in better ways considering P-set, Q-set and Run $P Q$ method.

4. Table1 can be summarized through graphical interface to observe the overall agreement or disagreement in different category. Box plot or other similar plot will attribute final factor loadings better after rotation presented in Table 2.

5. The novelty of the proposed approach is not clear. Please explain exactly how the overall approach is better and effective compare to other existing methods.

6 . The abstract remains quite vague about the results; more specific and quantitative results should be included in the abstract.

7. Although there is no support for higher levels of citizen engagement, how effective will be citizen science as a form of public participation? Please explain and discuss.

Printer-friendly version

Discussion paper

\section{(1)}


8. In page 2, paragraph 3 , line 24 of the manuscript, mentioned "although they also indicated they doubts". Not clear enough. Please check.

9. In page 20 , paragraph 2 , line 5 of the manuscript"There appears to be a mismatch between the intentions of the participants and the way they trust citizens with the level of participation" - need more clear views.

10. In page 21 , line 9-10,"The correlation between Factor $A$ and $C$ was 0.43 , which indeed indicates that they are interrelated and overlap. Typically correlations above 0.39 are considered significant". What will be conclusion if the correlation between Factor $\mathrm{A}$ and $\mathrm{C}$ was 0.4 or 0.35 . Please explain.

11. Understanding uncertainty as well as quantification is important in water management practice [Shoaib et al., 2016]. If the impact of uncertainty is properly explained as a form of public participation, understanding about government practitioners' acceptance and perception of citizen science will be more effective. Adding uncertainty dimension, surely add light in the proposed approach.

\section{REFERENCES}

Clark, M. P., et al. (2015), A unified approach for process-based hydrologic modeling: 1. Modeling concept, Water Resources Research, 51(4), 2498-2514.

Shoaib, S. A., L. Marshall, and A. Sharma (2016), A metric for attributing variability in modelled streamflows, Journal of Hydrology, 541, Part B, 1475-1487.

Interactive comment on Hydrol. Earth Syst. Sci. Discuss., doi:10.5194/hess-2016-463, 2016. 